\title{
CLIMATE CHANGE EDUCATION CURRICULUM FOR NIGERIA TERTIARY EDUCATION SYSTEM
}

\author{
ALIYU, ABDULLAHI DADA (PhD) AND UMAR, MUHAMMAD
}

\begin{abstract}
The paper attempted to propose a Climate Change Education Curriculum that is conceived to provide a clear understanding of the Climate Change phenomenon for students in Tertiary institutions in Nigeria. Nobody is left in doubt of the relevance of cilmate change education in Nigeria tertiary education system. Tertiary educational institutions are expected to play a proactive role on proffering solutions to the climate change challenges facing Nigeria. What needs to be done is to harness resources toward putting in place a well-articulated climate change education curriculum that should provide requisite information/knowledge and skills for future leaders. Thus, it is recommended that cogent policies needs to be developed to ensure that climate change education is fully integrated into tertiary education system in Nigeria; that climate change education curriculum should be offered either as a standalone specialized course or integrated within other courses; and professional development support be provided to educators so as to be able to deliver effectively and also to be able to develop relevant teaching materials on climate change that could stand the test of time.
\end{abstract}

Key Words: Climate Change, environment, globalization, adaptation, and mitigation

\section{Introduction}

Apart from Terrorism, Climate change is one of the most devastating phenomena that has attracted greater concern from all and sundry. Climate change is such that one does not need the highest educational qualification to actually understand that something is amiss around us today. From the ever increasing desert encroachment, deforestation, erosions, unhealthy waters, atmospheric pollution, over flooding and many other environmental problems, one does not need to be told that conditions are changing. What remains to be clearly understood is the 'how and why' of the climate change and what needs to be done. According to Susan (2002) Climate change is a great topic for students to study because it integrates so many subjects: energy, environment, geography, politics, chemistry, biology, economics, and more. It requires students to use analytical tools and mathematical skills, and to exercise their abilities to research, think and understand complex issues.

What is more is that there are a number of widely held misconceptions about climate change, and unfortunately, these are reflected in some of the educational materials available. It is therefore crucial to design a well-conceived curriculum which will provide students with accurate information and be careful not to reinforce common but incorrect notions. This is the intent of this paper. Thus, the paper 'Climate Change Education Curriculum for Nigeria Tertiary Education System' attempted to present a Climate Change Education Curriculum that is precise in its outlook but rich in trying to provide a clear understanding of the Climate Change phenomenon for students in Tertiary institutions in Nigerian. In the paper, issues discussed included Education and Climate Change; the Need for Climate Change Education Curriculum; considerations for a Climate Change Curriculum; and the Climate Change Education Curriculum. Thereafter, 
conclusions and recommendation were drawn on how best to take advantage of the curriculum provisions.

\section{Climate Change Education}

Climate change is a reality and complex issue, particularly as it relates to its causes and consequences. Climate change, or global weather patterns, or global warming can be described as the biggest environmental issue of our time. It is global in its causes but its consequences are far more reaching in developing countries, particularly Nigeria. It is a topical issue worldwide because of its attendant problems that are threatening the sustenance of man and environment.

Climate change has been thought of as a phenomenon created by nature and human beings, which devastates the earth and causes hardship of unpredicted magnitude to living and survival Intergovernmental Panel on Climate Change (IPCC, 2010). It is also referred to as global warming or weather patterns. Udenyi (2010) opined that climate change is simply a change in the climate condition of the world and that the change is found by the scientists and others to be on the negative. United Nation on Environmental Programme (UNEPA, 2008), defines climate change as extreme reactions of the weather phenomenon which creates negative impact on agricultural resources, water resources, human health, depletions of ozone layer, vegetations, soil and doubling of $\mathrm{Co} 2$ in the ecosphere. Omotosho (2007) defines climate change as a change of climate that is attributable directly or indirectly to human activities and, which alters the composition of the global atmosphere, in addition to natural climate variability observed over comparable time periods.

Patterns of change in the environment and climate have been observed over time. In its simplest form, experiences have shown that compared to the pre-Industrial era, temperature has warmed up much more than what it used to be (before now, in degree centigrade). The major causes for this warming have been attributed to what is termed 'the rising stocks of greenhouse gases in the atmosphere', including carbon dioxide $\left(\mathrm{CO}_{2}\right)$, methane $\left(\mathrm{CH}_{4}\right)$, nitrous oxide $\left(\mathrm{N}_{2} \mathrm{O}\right)$, chloro-and fluoro-carbons and a number of other gases that arise from industrial processes. According to Sebastian, August, Aissetou, Steven and John (2009) current level or stock of greenhouse gases in the atmosphere is estimated to be equivalent to 430 parts per million (ppm) of carbon dioxide compared to $280 \mathrm{ppm}$ before the industrial revolution (Stern, 2006). It has been asserted that if business is continuing as usual, it is predicted that by the end of 2035 , there would be a $2^{\circ} \mathrm{C}$ increase in temperature. It is clear that climate change will impact heavily on agriculture and renewable natural resources. This means that our current practices may have to change significantly to adapt to and mitigate the climate change, using education as a mechanism.

Education can mitigate climate change through a viable climate change curriculum. Education can be described as the process of preparing an individual to become a functional and acceptable member of society. Two concepts are inbuilt in the definition of education, namely: creation of knowledge and experience, and growth and development. Education is able to respond to societal challenges and expectations.

Thus, climate change education can be thought of as the embodiment of knowledge, skills and experience on the phenomena of climate change. According to Sebastian, August, 
Aissetou, Steven and John (2009) climate change education is the body of knowledge on the causes and consequences of climate change.

It has long been accepted throughout the world, that Tertiary Education plays a critical and vital role in preparing and providing the needed leadership to meet the challenges of climate change and to stimulate sustainable development (Bloom et al., 2005). Tertiary Education in particular is well placed to contribute to this process. What is needed is a curriculum that would facilitate clear understanding of climate issues, stimulating and/or sustaining attitudinal change in the individuals who in turn could influence policies at organisational levels (Gardner, 2002). Gardner emphasised that learners who are educated about the importance of conserving the environment today could be the industry owners or managers tomorrow. Therefore, it makes sense to raise awareness to students now so that they make the right decisions in the future. There is always an opportunity to infuse climate change education in teaching and learning at various stages of the learning process. For instance, Mommers (2002) is of the view that "when an educator is teaching science, it is much easier to talk about climate change." She emphasized that teaching materials (of whatever type) when properly used allow students to participate, which makes learning much easier and enjoyable.

\section{Curriculum Provision on Climate Change Education in Nigeria's Tertiary Education}

What obtains currently in Nigerian institutions as provisions on climate change are basically found as follows:

1. Knowledge of ecosystems as a traditional focus in the Science (biology, chemistry, integrated science, agricultural science) curricular

2. The human impact on the quality of the environment as emphasized in both Social Studies (including Geography) and Integrated Science. Social Studies deals with human systems and touches on most knowledge learning outcomes, including more on traditional practices than

3. Environmental Education- This is a new discipline or course of instruction in some higher institutions in Nigeria. Its impact is yet to be fully appreciated

4. The Need for Climate Change Education Curriculum in Nigeria Tertiary Education

Increasingly, climate change has become a challenge because of its ever increasing risks and uncertainties on human habitation and survival. This has made it pertinent for all students to be well informed about the challenges posed by climate change. This is more so if they are expected to, more appropriately, make any difference in the organisations and/or communities they find themselves. They also need to understand the implications of climate change to economic and societal development.

Educating those currently in school, particularly those in tertiary institutions about climate change will help to shape and sustain future policy-making as well as many sectors of development. Gardner (2004: 29) is of the view that students should be able to contribute to the development of the body of knowledge as regards climate change. And that:

There is the need for students to be aware of the various International Conventions and Protocols surrounding climate change. These include UN Framework convention on climate change (UNFCCC), Kyoto protocol and a range of other informal partnerships 
and dialogues that provide a framework that supports co-operation, and a foundation from which to build further collective action.

The challenges are to develop good curriculum, produce relevant learning resources that capacitate educators for effective delivery, leading to active student participation in the learning process at the tertiary level of education. This is in view of the policy making and implementation role of graduates of this level of education. This requires collective endeavour from a wider spectrum of key players including the academia in Nigeria, through research and development. There is no doubt that Nigeria stands to benefit from this gesture as a nation member faced with the challenges of the global phenomena of climate change.

\section{Considerations for Developing Climate Change Education Curriculum}

The curriculum is indeed a crucial component of any educational process. It is thought of as a written plan to be acquired or delivered in institutions of learning. Curriculum on climate change education is intended to foster awareness of and concern for environmental issues that aid in developing new patterns of behaviour that will promote environmental responsibility.

Given the complexity of today's ever-changing world, the International Bureau for Education (IBE) advocate for contemporary approaches to curriculum development (for existing and new disciplines)in such a manner that it would be clearly distinguished from the traditional understanding of curricula as merely plans of study or lists of prescribed content. Indeed, it is commonly accepted that in order to effectively foster learning, educational content, methods and structures need to be permanently adjusted to changes occurring in science, technology, culture, economy and social life.

Education authorities around the world are increasingly addressing the challenge of improving the quality of learning outcomes through curricular reform, and responding to new demands by providing skills and building competences that are relevant to local and global needs. Despite the differences of approach, authorities are generally looking into new solutions to improve the quality of learning outcomes based on curriculum provisions that take into account different criteria. Obanya (1995) says the way a curriculum is conceptualized in theory and then designed, organized and developed for practical implementation depends on a country's particular philosophy of education, on its national, social, cultural, economic, developmental aspirations, on where it considers the main stream of emphasis should lie. Should cultural and societal needs or the demands for economic development determine the nature of the curriculum? Should the curriculum be geared to the interests of the child or should it be based on the disciplines of knowledge? Should the emphasis be on generalism or on specialism? Should there be a common curriculum for all pupils or should there be different curricula for different pupils? How much emphasis should be given to issues, such as learning theory, methodology, how much to situational (local) considerations, e.g. urban, rural, ethnic, community schools? Depending on one's answer to such basic questions of curriculum as to what should be taught, why, to whom, in what manner (i.e. how), where will our conventionalization of the pattern of curriculum take shape. According to Bishop (1985), the conceptualizations of the design and organization of the curriculum have important repercussions on other key processes of curriculum - namely, the day to day 
implementation implications, the role of the teacher, methodology, diffusion of innovation, evaluation etc.

Due to the increased access to international comparisons in education, countries are also keen" to improve their education systems and curricula, adopting as a reference 'good' policies and practices and international 'standards' such as those outline by IBE and UNFCCC in order to meet the challenges and opportunities of the knowledge society and of an increasingly interdependent world. In general, there is a need for increased exchanges, the sharing of experiences, learning from both failures and successes, and capitalising on local experiences and traditions. What all this means is that whatever is being conceived as climate change education curriculum should be planned or developed alongside internationally accepted set standard or specifications, while hinging same to local dictates or demands and peculiarities.

\section{Designing the Climate Change Education Curriculum}

Curriculum design consists of those considerations having to do with the contents, the form, and the arrangement of the various elements of a curriculum. It is important to distinguish between curriculum planning and instructional planning with curriculum planning being the antecedent task. Curriculum planners are forced to make design decisions almost from the outset of their work.

The design decisions should revolve around three important considerations:

1. The range of school levels and schools to be covered by the curriculum,

2. The number of elements to be included in the curriculum, and

3. The nature and scope of each of those elements.

Today, education system is facing the challenges of globalization, but at the same time education is needed or expected to support the building of social cohesion and the fostering of indigenous cultures to sustain a sense of identity and belonging amongst people. With a clear cut rationale and/or objectives, curriculum design on climate change education may include:

i. providing understanding and appreciation of the climate change phenomena;

ii. identifying and resolving environmental problems and issues in the immediate and distant environment; and

iii. understanding alternative adaptation and/or mitigation strategies for climate change problems.

Essentially, the climate change education curriculum should:

i. Provide a broad introduction into various aspects of the physical and social dimensions of climate change.

ii. It should discuss different aspects of climate change in detail, giving examples using localised environmental scenes.

iii. The curriculum could be grouped into three broad categories, viz: the climate system (including nature, changing patterns), impacts (adverse effects), and adaptation strategies. 
A breakdown of what the curriculum may entail is here proposed:

Table 1: Description of the proposed Climate Change Education Curriculum

\begin{tabular}{|c|c|}
\hline $\mathrm{R} \quad \mathrm{E}$ & \begin{tabular}{l|llllllllllllllllll}
$\mathrm{A}$ & $\mathrm{A}$ & $\mathrm{S}$ & $\mathrm{P}$ & $\mathrm{E}$ & $\mathrm{C}$ & $\mathrm{T}$ & $\mathrm{S}$ & $\mathrm{T}$ & $\mathrm{O}$ & $\mathrm{B}$ & $\mathrm{E}$ & $\mathrm{T}$ & $\mathrm{A}$ & $\mathrm{U}$ & $\mathrm{G}$ & $\mathrm{H}$ & $\mathrm{T}$ \\
\end{tabular} \\
\hline Introduction to Climate Change & 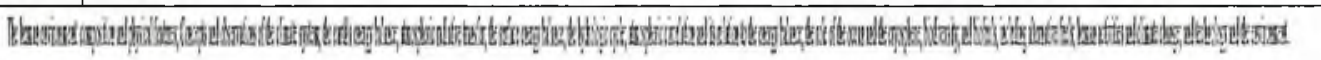 \\
\hline $\begin{array}{l}\text { Impact of Climate } \\
\text { Change }\end{array}$ & 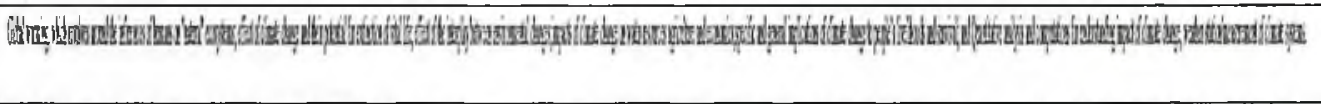 \\
\hline Adaptation/Mitigation & 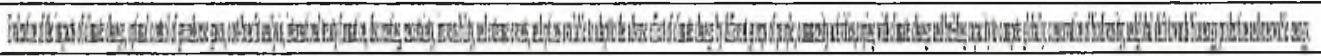 \\
\hline 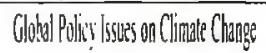 & 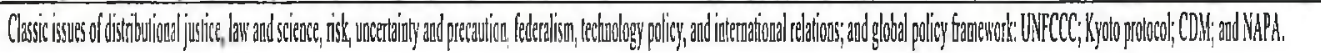 \\
\hline
\end{tabular}

Resources for the Climate Change Education Curriculum Delivery

As earlier highlighted by Mommers (2002) the curricula provisions are such that could be taught across the lines of other conventional subjects like in the sciences - biology, physics, geography, engineering and technology, as well as in subjects such as history, civic education, etc. Better still, the curriculum can be put to use separately or wholly as a specialized programme of instruction, as a partial requirement for the award of a Certificate, Diploma or Degree or such higher qualification. The programme could equally be taught or learnt as a general studies (GENS/GSE) course requirement. In any case the institution may devise its ways of spreading the climate change education content within its structure.

In teaching about climate change, instructional materials abound that can be taking advantage of. From the local scenes in the learners' environment to the use of ecommunicative (virtual) media, teaching and learning can be made much easier, lively and realistic. Clips, Captions and/or Charts from sites such as desert sand dunes, heavy rains storm and devastating effect of flooding disasters like Tsunami, Huricane Catrina, gully erosions, smoky scene of industrial localities, (in most cities or towns), water and environmental pollution, as well as technological disasters (like industrial/toxic wastes, effect of Nuclear disasters like Hukushima, Japan and Chenobyl,) and their aftermaths, could be used to make teaching and learning real.

Actual teaching should involve the interplay of conventional and contemporary instructional methods and techniques, including the use of relevant multimedia platforms. As much as possible, problem solving, activity based, concept mapping, conceptual change, longitudinal studies and record keeping/documentation, explorative, inquiry, expository and community based instructional techniques should be the centre point of classroom interaction. Emphasis should equally be placed on the meta-cognitive aspect of learning as well as collaborative learning, as teaching strategies.

The evaluative process should centre on community based projects and group works, rather than mere tests, which has always characterized our educational process. As much as possible, novel ideas, creativity, reflective thinking and ability to solve problem(s) on the part of students should be rewarded promptly.

\section{Conclusion}

Nobody is left in doubt of the relevance of climate change education in Nigeria tertiary education system. Tertiary educational institutions are expected to advice on solutions to the climate change challenges facing Nigeria. What needs to be done is to harness 
resources toward putting in place a well-articulated climate change education curriculum that should provide requisite information/knowledge and skills for future leaders. There is currently an urgent need to integrate climate change into the curricula whether as a fullfledged course or as a component within other courses. The graduates of tertiary education need to have a full grasp of the science of climate change and its implications on the livelihoods of the communities they will be serving. Equipped with the necessary knowledge, the graduates will be able to advise on adaptation and mitigation strategies depending on situation.

\section{Recommendations}

The following recommendations are put forward:

1. The Federal Government of Nigeria (through appropriate Education agencies eg NUC, NCCE, NABTE, etc.) should develop cogent policies to ensure that climate change education is fully integrated into tertiary education system in Nigeria.

2. Tertiary institutions should develop climate change education curriculum that would be offered either as a standalone specialized course or integrated within other courses.

3. Tertiary institutions and relevant agencies should support the professional development of educators to be able to deliver effectively and also to be able to develop relevant teaching materials on climate change.

4. Tertiary institutions and relevant agencies should promote institutional collaboration and networking within Nigeria and worldwide focusing on climate change and other emerging issues.

5. The Federal Government of Nigeria (through appropriate Education agencies eg NUC, NCCE, NABTE, etc.) should promote the development of sustainable mechanisms for funding climate change education in Nigeria.

6. The Federal Government of Nigeria (through appropriate Education agencies eg NUC, NCCE, NABTE, etc.) should encourage and/sustain research into climate change issues that would lead to better understanding and appreciation of the climate change phenomenon. 


\section{References}

Bishop (1985). The teacher and the Curriculum. Ibadan: TGE.

Gardner, G. (2004). In Mantoe, P. (2010). Education Can Change the Climate. Canada: Terraviva/IPS. Posted on 02 December 2010

International Bureau for Education (2009). Training Tool for Curriculum Development: A Resource Pack. Tanzania: UNESCO-IBE.

Intergovernmental Panel on Climate Change (2010). Fourth Assessment Report: Climate Change 2007: Working Group II: Impacts, Adaption and Vulnerability. http://www.ipcc.ch/publications and data/ar4. Retrieved on 7/9/2012

Mommers, M. L. (2002).Hammering out a Deal on Climate Change. In Mantoe, P. (2010). Education Can Change the Climate. Canada: Terraviva/IPS. Posted on 02 December 2010 by terna

Obanya, P. (1995) "Case studies of Curriculum innovations in West Africa" .In Tai Afrik (Ed) Basic Adult and Non-formal Education Curricula: A sub-Saharan African Senario. Senegal: UNESCO

Sebastian C.; August, B. T.; Aissetou Y.; Steven M. \& John, D. K. S. (2009). Mainstreaming Climate Change into Agricultural Education: Challenges and Perspectives. ICRAF Working Paper no. 82. Nairobi, Kenya: World Agro forestry Centre.

Susan, J. H. (2009). Teachers' Guide to High Quality Educational Materials on Climate Change and Global Warming. USA: Carnegie Mellon University.

Udenyi O. G. (2010). Impacts of Climate Change. Nigeria: Social Network

United Nations Environmental Programme (2008). Scoping Paper for Expert Group Meeting on Climate Change Adaptation. African Minister Conference on the Environment 12th Meeting of the Expert Group TBC. http://www.unep.org/roa/About_AMCEN/default.asp 